light of this further evidence of its harmful effects on the quality of patient care. Furthermore, the research suggests a wealth of barely tapped potential among NHS ancillary staff. Those who are content with their jobs should be helped to do them in a satisfying way, but others who could move into more demanding roles should be offered training and development opportunities. Possibilities already exist herefor example, Workbase is a trade union project backed by the NHS Training Authority that promotes and provides training for manual workers. ${ }^{3}$ Another option is experimenting with new roles such as care assistant which combine domestic and nursing responsibilities. ${ }^{+}$

Most striking of all, however, is an implicit lesson that is relevant to everyone in the NHS. Better standards of care may be achieved only by highly motivated staff in all types of work and at all levels in the organisation. The way to encourage people to care more about their work is to care more about them, whether they are a cleaner or a consultant.

JANE SALVAGE

Director,

Nursing Developments,

King's Fund Centre for Health Services Development, London NW1 7NF

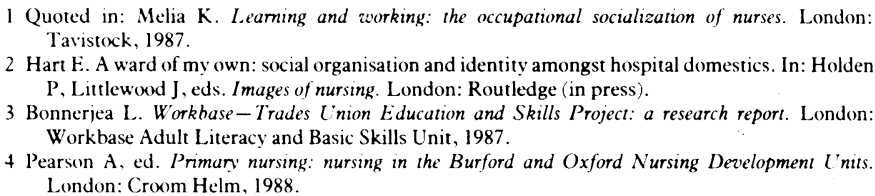

\title{
The obstetric problems of the thalidomide children
}

\section{An increased caesarean section rate but no increase in malformations}

The women who were born affected by thalidomide have been old enough to reproduce for about a decade, and a recent British survey identified 35 such women who had had 64 live births and six miscarriages. ${ }^{1}$ There were no reports of death or malformation among the viable children. This confirms what would be expected: that thalidomide is a teratogen which acted chemically at a specific site in embryonic development and has not caused developmental problems for the next generation.

Thalidomide appeared in the mid-1950s and was greeted warmly because, unlike the barbiturates used as sedatives up to then, it was not lethal in overdose. Then in the early 1960s it was realised that if taken by a pregnant woman in the early weeks of gestation it could produce specific abnormalities. McBride in Australia and Lenz in Germany reported the association between thalidomide and the absence or abnormalities of limbs. ${ }^{23}$ This was soon confirmed in Britain, ${ }^{+5}$ and the drug was rapidly withdrawn. Eventually some 820 affected children were born alive in Britain and 2800 in West Germany.

Thalidomide is a powerful teratogen if the fetus is exposed between the 37 th and 50 th day of life - that is, five to seven weeks after the last normal menstrual period. This time span is specific, and many women took thalidomide later in pregnancy with no problems. In a report almost 20 years after the episode the medical officer of the Thalidomide Trust estimated that some 450 young people still survived and listed the abnormalities found in 389 of them. ${ }^{6}$ By far the commonest were limb deficiencies: a third of the patients had all four limbs affected and a half had two limbs affected. Occulomuscular palsies and ear deficiencies were also common, and many showed dwarfism and stunted growth. Pelvic examination was not performed specifically, but five gynaecological defects were reported - a bicornuous uterus in one case and two cases each of vaginal atresia and vesicovaginal fistulae.

Most of the women affected by thalidomide were thus physically able to reproduce, and the coarse measures of perinatal mortality and miscarriage rates are in the same range as for the total population, given the small numbers reported from the British survey.' The incidences of pre-eclampsia, preterm labour, urinary tract infection, and twin pregnancy were also similar. A fifth of the deliveries were by caesarean section. The authors broke down the population of women into those with mild disabilities and those with absent limbs. Nine of the 12 mothers with absent lower or upper limbs were delivered by caesarean section. Among the 28 women with minor disabilities there were only five caesarean sections in 52 deliveries - a rate similar to that seen in the general population. The increased caesarean section rate of the group with limb problems was associated with cephalopelvic disproportion that often followed changes in the lower lumbar region affecting the shape of the pelvis.

Other problems reported in the survey were mechanical difficulties in measuring the woman's blood pressure and the increased effort the mother had feeding and looking after her children. Episiotomies that resulted in pain restricted the use of the mother's feet, which made life difficult for some mothers as they used their feet as substitutes for a missing or malformed hand.

The results of this survey are reassuring: they confirm all that was said at the time about the thalidomide problem. The use of caesarean section in good hospitals with proper anaesthesia is a low risk procedure in this group, but we are still left with the problem that the women may have in bringing up their children in the 1990s.

Professor of Obstetrics and Gynaecology,

GEOFFREY CHAMBERLAIN

St George's Hospital Medical School,

London SW17 0RE

1 Maouris PG, Hirsch PJ. Pregnancy in women with Thalidomide induced disabilities. Br $f$ Obstet Gvnaecol 1988;95:717-9.

2 McBride W. Thalidomide and congenital abnormalities. Lancet 1961;ii:1358.

3 Lenz W. Thalidomide and congenital abnormalities. Lancet 1962;i:45.

4 Spiers A. Thalidomide and congenital abnormalities. Lancet 1962;i:303-5.

5 Smithells R. Thalidomide and malformations in Liverpool. Lancet 1962;i:1270-3.

6 Quibell E. Thalidomide embryopathy. Practitioner 1981;25:721-6.

\section{Correction}

\section{Smoking and leukaemia}

Several printing errors occurred in this editorial by Professor Nicholas Wald (10 September, p 638). Reference 2 should have appeared at the end of the third sentence in the second paragraph, and reference 3 should have been deleted, reference 4 then becoming reference 3 . The eighth sentence in the third paragraph should have read, "Social class would if anything tend to mask the association between smoking and leukaemia as leukaemia is more common among people in professional occupations but smoking is more common among people in partly skilled and unskilled occupations.” 